\title{
EFIKASI HERBISIDA ATRAZIN TERHADAP GULMA DAN PERTUMBUHAN SERTA HASIL TANAMAN JAGUNG (Zea mays L.)
}

\author{
Study of Efficacy Atrazine Herbicide on Weeds and Plant Growth and \\ Production of Corn (Zea mays L.)
}

\author{
Zam Zami $^{1}$, Herry Susanto ${ }^{1) *}$, Kuswanta Futas Hidayat ${ }^{1}$, Hidayat Pujisiswanto ${ }^{2}$ \\ 1) Jurusan Agroteknologi, Fakultas Pertanian, Universitas Lampung \\ Jalan Sumantri Brojonegoro No. 1 Bandar Lampung, 35145 \\ *E-mail: herry.susanto@fp.unila.ac.id
}

\begin{abstract}
ABSTRAK
Salah satu herbisida yang dapat digunakan untuk mengendalikan gulma pada tanaman jagung adalah herbisida atrazin. Penelitian bertujuan untuk mengetahui efektivitas atrazin dalam mengendalikan gulma pada pertanaman jagung, mengetahui apakah terjadi perubahan komposisi jenis gulma pada pertanaman jagung setelah aplikasi herbisida atrazin, dan mengetahui apakah penggunaan herbisida atrazin dapat menyebabkan terjadinya fitotoksisitas dan menghambat pertumbuhan serta menurunkan hasil tanaman jagung. Penelitian dilakukan di lahan petani Desa Hajimena, Kecamatan Natar, Kabupaten Lampung Selatan dan Laboratorium Gulma, Fakultas Pertanian, Universitas Lampung pada bulan November 2019 sampai Maret 2020. Penelitian disusun dalam Rancangan Acak Kelompok (RAK) dengan empat ulangan dan enam perlakuan yaitu herbisida atrazin dosis $1,20 \mathrm{~kg} / \mathrm{ha}, 1,80 \mathrm{~kg} / \mathrm{ha}$, $2,40 \mathrm{~kg} / \mathrm{ha}, 3,00 \mathrm{~kg} / \mathrm{ha}$, penyiangan manual, dan kontrol. Hasil penelitian menunjukkan bahwa herbisida atrazin dosis $1,20-3,00 \mathrm{~kg} / \mathrm{ha}$ efektif dalam mengendalikan gulma total di areal tanaman jagung hingga $6 \mathrm{MSA}$, herbisida atrazin menyebabkan terjadi perubahan komposisi gulma pada 3 dan 6 MSA dari gulma Richardia brasiliensis menjadi gulma Calopogonium mucunoides, dan aplikasi herbisida atrazin dosis 1,20-3,00 kg/ha tidak menyebabkan terjadinya fitotoksisitas dan tidak menghambat pertumbuhan serta tidak menurunkan hasil tanaman jagung.
\end{abstract}

Kata kunci: atrazin, gulma, herbisida, jagung

\begin{abstract}
One of the herbicides that can be used to control weeds on corn cultivation is the atrazine herbicide. The aim of this study was to determine the effectiveness of atrazine in controlling weeds in corn, to determine whether there was a change in the composition of weeds in corn after application of the atrazine, and to determine whether the use of atrazine herbicide could cause phytotoxicity and inhibit growth and reduce corn yield. The research was conducted on farmer's land in Hajimena Village, Natar District, South Lampung Regency and Weed Laboratory, Faculty of Agriculture, University of Lampung from November 2019 to March 2020. The research was arranged in a randomized complete block design (RCBD) with four replications and six treatments, namely the herbicide atrazine doses of $1,20 \mathrm{~kg} / \mathrm{ha}, 1,80 \mathrm{~kg} / \mathrm{ha}, 2,40 \mathrm{~kg} / \mathrm{ha}$, $3,00 \mathrm{~kg} / \mathrm{ha}$, manual weeding, and control. The results showed that atrazine herbicide doses of 1,20-3,00 $\mathrm{kg} / \mathrm{h}$ a were effective to control of weeds total on corn area up to 6 weeks after application, atrazine herbicide caused change on weed composition of Richardia brasiliensis become Calopogonium mucunoides at 3 and 6 weeks after application, and the application of atrazine herbicide doses of 1,20-3,00 kg/ha did not cause phytotoxicity, inhibit corn growth, and decrease yields.
\end{abstract}

Keywords: atrazine, weed, herbicide, corn 


\section{PENDAHULUAN}

Tanaman Jagung (Zea mays L.) merupakan tanaman pangan sumber karbohidrat yang termasuk famili Poaceae. Jagung adalah bahan pangan terpenting kedua setelah padi di Indonesia. Menurut Badan Pusat Statistik (2019), produksi jagung di Indonesia tahun 2017 adalah sebesar 28,92 juta ton. Produksi ini mengalami peningkatan dari tahun sebelumnya yang hanya sebesar 23,57 juta ton. Pada tahun 2017 Indonesia masih melakukan impor jagung sebesar 278,57 ribu ton. Hal tersebut disebabkan produksi jagung di Indonesia belum mencukupi kebutuhan masyarakat Indonesia yang setiap tahunnya semakin meningkat.

Banyak faktor yang menyebabkan produksi jagung rendah salah satunya disebabkan oleh gulma. Berdasarkan penelitian Craff dan Reynor (2001), jika gulma pada lahan jagung tidak dilakukan pengendalian maka penurunan hasil tanaman akan terjadi berkisar 18-60\%. Oleh sebab itu, pengendalian gulma merupakan hal penting yang harus dipertimbangkan untuk meningkatkan produksi tanaman jagung sehingga dapat memenuhi kebutuhan masyarakat secara berkelanjutan. Metode pengendalian gulma yang dapat digunakan salah satunya adalah dengan menggunakan herbisida kimiawi.

Penggunaan herbisida kimiawi dimaksudkan agar tidak memberi pengaruh terhadap tanaman budidaya tetapi berpengaruh terhadap pertumbuhan gulma. Oleh karena itu, dibutuhkan herbisida atau zat yang bersifat selektif dan tepat dalam mengendalikan gulma.

Herbisida kimiawi yang dapat digunakan untuk pengendalian gulma pada tanaman jagung, salah satunya adalah herbisida atrazin. Menurut Tomlin (2011) herbisida atrazin merupakan herbisida pratumbuh yang memiliki sifat selektif untuk tanaman jagung, sehingga dapat diaplikasikan tanpa meracuni tanaman. Gejala yang ditimbulkan pada gulma akibat teracuni atrazin akan mengalami klorosis yang dimulai dari tepian daun dan menyebar kebagian lainnya hingga gulma mengalami kematian. Aplikasi herbisida atrazin diharapkan dapat mengendalikan gulma pada lahan sehingga mampu mengurangi kerugian akibat kompetisi dari gulma dengan tanaman budidaya. Oleh karena itu, dilakukan pengujian untuk mengetahui efektivitas berbagai dosis herbisida atrazin dalam mengendalikan gulma pada pertanaman jagung, sehingga dapat diketahui daya kendali herbisida atrazin terhadap pertumbuhan gulma dan tingkat fitotoksisitasnya pada tanaman jagung.

\section{METODE PENELITIAN}

\section{Alat dan Bahan}

Alat-alat yang digunakan antara lain sprayer semi otomatis bernosel merah, gelas ukur, jangka sorong, timbangan digital, oven, moisture tester, kuadran $0,5 \mathrm{~m}$ x 0,5 $\mathrm{m}$, kamera, dan alat tulis. Bahan-bahan yang digunakan pada penelitian yaitu benih jagung hibrida (Pioneer 27), pupuk N, pupuk $\mathrm{P}_{2} \mathrm{O}_{5}$, pupuk $\mathrm{K}_{2} \mathrm{O}$ dan herbisida Atrazin $80 \%$.

\section{Rancangan Percobaan}

Penelitian menggunakan metode Rancangan Acak Kelompok (RAK) dengan 4 ulangan. Perlakuan terdiri dari : herbisida berbahan aktif atrazin $80 \%$ dengan dosis perlakuan herbisida atrazin dosis $1,20 \mathrm{~kg} / \mathrm{ha}$, $1,80 \mathrm{~kg} / \mathrm{ha}, 2,40 \mathrm{~kg} / \mathrm{ha}$ dan $3,00 \mathrm{~kg} / \mathrm{ha}$, penyiangan manual, dan kontrol yaitu tanpa pengendalian gulma.

\section{Tahapan Penelitian}

Satu satuan dalam percobaan ini adalah petakan yang terdiri dari 5 juring tanaman tebu dengan panjang juring $10 \mathrm{~m}$ dan jarak antarjuring $1,5 \mathrm{~m}$ serta antar ulangan $2 \mathrm{~m}$. Jumlah bibit yang digunakan setek terdiri mata tunas 10 per meter. 
Pengaturan letak percobaan dan kelompok diusahakan sedemikian rupa sehingga lokasi percobaan dengan kondisi gulma sasaran yang merata.

Petak percoban berukuran $4 \mathrm{~m} \times 7 \mathrm{~m}$ dengan jarak tanam $75 \mathrm{~cm}$ x $25 \mathrm{~cm}$. Herbisida atrazin diaplikasikan satu kali yaitu pada 2 hari setelah tanam (HST) dengan menggunakan sprayer semi otomatis dengan lebar bidang semprot $2 \mathrm{~m}$ dan volume semprot 466 1/ha.

Pengamatan gulma dilakukan pada petak contoh berukuran $0,5 \mathrm{~m} \times 0,5 \mathrm{~m}$. Jumlah petak contoh yang diambil dua titik untuk setiap satuan petak percobaan pada setiap pengambilan sampel gulma. Pengambilan sempel gulma dilakukan sebanyak dua kali yaitu pada 3 dan 6 minggu setelah aplikasi (MSA). Gulma yang diambil kemudian dipilah berdasarakan spesiesnya dan dikeringkan dengan menggunakan oven dengan suhu $80^{\circ} \mathrm{C}$ selama 48 jam mencapai bobot konstan.

Homogenitas ragam data diuji menggunakan Uji Bartlett dan aditivitas data diuji dengan menggunakan Uji Tukey. Asumsi anara terpenuhi, maka data akan dianalisis dengan sidik ragam dan pemisahan nilai tengah perlakuan dilanjutkan dengan Uji Beda Nyata Terkecil (BNT) pada taraf 5\%.

Variabel pengamatan meliputi bobot kering gulma total, bobot kering gulma golongan daun lebar, bobot kering gulma golongan rumput, koefisien komunitas (C), tinggi tanaman, panjang tongkol, diameter tongkol, bobot kering jagung pipilan, bobot 100 butir, dan fitotoksisitas tanaman.

\section{HASIL DAN PEMBAHASAN}

\section{Bobot Kering Gulma Total}

Herbisida atrazin pada dosis 1,20 $3,00 \mathrm{~kg} / \mathrm{ha}$ mampu mengendalikan gulma total pada 3 dan 6 minggu setelah aplikasi (MSA) (Tabel 1). Hal ini sesuai dengan penelitian Mustajab et al. (2014) bahwa herbisida atrazin mampu menekan pertumbuhan gulma total dengan baik pada lahan budidaya tanaman jagung hingga 6 MSA dengan bobot kering perlakuan penyiangan manual tidak berbeda dengan perlakuan herbisida.

Tabel 1. Pengaruh aplikasi herbisida atrazin terhadap bobot kering gulma total

\begin{tabular}{|c|c|c|c|c|}
\hline \multirow[b]{2}{*}{ Perlakuan } & \multicolumn{2}{|c|}{3 Minggu Setelah Aplikasi } & \multicolumn{2}{|c|}{6 Minggu Setelah Aplikasi } \\
\hline & Asli & $(X+0,5)$ & Asli & $\sqrt{ } \sqrt{ }(X+0,5)$ \\
\hline & \multicolumn{4}{|c|}{$\ldots \ldots \ldots \ldots \ldots . . .\left(\mathrm{g} / 0,5 \mathrm{~m}^{2}\right)$} \\
\hline Atrazin $1,20 \mathrm{~kg} / \mathrm{ha}$ & 0,37 & $0,92 \mathrm{~b}$ & 17,40 & $2,00 \mathrm{~b}$ \\
\hline Atrazin $1,80 \mathrm{~kg} / \mathrm{ha}$ & 0,00 & $0,84 \mathrm{~b}$ & 11,93 & $1,79 \mathrm{~b}$ \\
\hline Atrazin $2,40 \mathrm{~kg} / \mathrm{ha}$ & 0,01 & $0,84 \mathrm{~b}$ & 12,32 & $1,83 \mathrm{~b}$ \\
\hline Atrazin $3,00 \mathrm{~kg} / \mathrm{ha}$ & 0,00 & $0,84 \mathrm{~b}$ & 7,82 & $1,63 \mathrm{~b}$ \\
\hline Penyiangan manual & 8,04 & $1,66 \mathrm{a}$ & 8,03 & $1,67 \mathrm{~b}$ \\
\hline Kontrol & 14,69 & $1,88 \mathrm{a}$ & 51,26 & $2,67 \mathrm{a}$ \\
\hline BNT $5 \%$ & & 0,28 & & 0,37 \\
\hline
\end{tabular}

Keterangan: Nilai tengah pada setiap kolom yang diikuti dengan huruf yang sama tidak berbeda nyata menurut uji BNT pada taraf $5 \%$

Pada 3 MSA herbisida atrazin dosis $1,20-3,00 \mathrm{~kg} / \mathrm{ha}$ mampu mengendalikan pertumbuhan gulma total dengan daya kendali tidak berbeda antardosis perlakuan yang digunakan, namun berbeda dengan kontrol dan penyiangan manual. Hal ini dikarenakan penyiangan manual dilakukan pada 3 MSA setelah pengambilan sampel gulma, sehingga kondisi pada perlakuan penyiangan manual sama seperti perlakuan kontrol yang tidak ada penyiangan setelah olah tanah dan tidak mengendalikan 
pertumbuhan gulma total. Sedangkan, pada 6 MSA herbisida atrazin dosis $1,20-3,00$ $\mathrm{kg} / \mathrm{ha}$ secara umum mampu mengendalikan gulma total dengan daya kendali yang tidak berbeda dengan penyiangan manual

\section{Bobot Kering Gulma Daun Lebar}

Data analisis vegetasi yang dilakukan menunjukkan pada petak percobaan didapat beberapa jenis gulma golongan daun lebar, yaitu Asystasia gangetica, Calopogonium mucunoides, Cleome rutidosperma, Commelina maculata, Croton hirtus, Euphorbia geniculata, Ipomoea triloba, Mimosa pudica, Oxallis barrelieri, Phyllanthus urinaria, Richardia brasiliensis, Spigelia anthelmia, dan Synedrella nodiflora.

Aplikasi Herbisida atrazin efektif mengendalikan gulma golongan daun lebar pada 3 dan 6 MSA (Tabel 2). Pada 3 dan 6 MSA herbisida atrazin dosis $1,2-3,0 \mathrm{~kg} / \mathrm{ha}$ mampu mengendalikan pertumbuhan gulma golongan daun lebar. Sesuai dengan laporan Pike (1994) pada penelitian yang dilakukan Midwest pada tahun 1972 - 1991 bahwa herbisida atrazin mampu mengendalikan gulma golongan daun lebar pada lahan tanaman jagung sampai dengan $74 \%$. Menurut Tomlin (2011), herbisida atrazin merupakan herbisida sistemik yang digunakan untuk mengendalikan gulma golongan daun lebar dan gulma golongan rumput dengan persistensi di lahan pertanian selama kurang lebih 58 hari.

\section{Bobot Kering Rumput}

Data penelitian menunjukkan bahwa pada petak percobaan didapat beberapa jenis gulma golongan rumput, diantaranya Digitaria cilliaris, Echinochloa colonum, Eleusine indica, dan Panicum repens. Herbisida atrazin mampu mengendalikan gulma golongan rumput hingga 6 MSA (Tabel 3).

Pada 3 MSA herbisida atrazin dosis $1,20-3,00 \mathrm{~kg} / \mathrm{ha}$ mampu mengendalikan gulma golongan rumput. Sedangkan, pada 6 MSA menunjukkan herbisida atrazin dosis $1,80-3,00 \mathrm{~kg} / \mathrm{ha}$ efektif menekan pertumbuhan gulma golongan rumput dengan daya kendali yang tidak berbeda dengan penyiangan manual. Sesuai dengan pendapat Williams et al. (2011), bahwa penggunaan herbisida atrazin baik tunggal maupun campuran mampu mengendalikan gulma golongan rumput dan golongan daun lebar.

Tabel 2. Pengaruh aplikasi herbisida atrazin terhadap bobot kering gulma golongan daun lebar

\begin{tabular}{|c|c|c|c|c|}
\hline \multirow[b]{2}{*}{ Perlakuan } & \multicolumn{2}{|c|}{3 Minggu Setelah Aplikasi } & \multicolumn{2}{|c|}{6 Minggu Setelah Aplikasi } \\
\hline & Asli & $X+0,5)$ & Asli & $\sqrt{ } \sqrt{ }(X+0,5)$ \\
\hline & \multicolumn{4}{|c|}{. } \\
\hline Atrazin $1,20 \mathrm{~kg} / \mathrm{ha}$ & 0,37 & $0,92 \mathrm{~b}$ & 8,20 & $2,87 \mathrm{~b}$ \\
\hline Atrazin $1,80 \mathrm{~kg} / \mathrm{ha}$ & 0,00 & $0,84 \mathrm{~b}$ & 8,10 & $2,87 \mathrm{~b}$ \\
\hline Atrazin $2,40 \mathrm{~kg} / \mathrm{ha}$ & 0,01 & $0,84 \mathrm{~b}$ & 6,10 & $2,55 \mathrm{~b}$ \\
\hline Atrazin 3,00 kg/ha & 0,00 & $0,84 \mathrm{~b}$ & 3,38 & $1,95 \mathrm{~b}$ \\
\hline Penyiangan manual & 7,40 & $1,62 \mathrm{a}$ & 7,13 & $2,66 \mathrm{~b}$ \\
\hline Kontrol & 13,96 & $1,85 \mathrm{a}$ & 28,81 & $5,39 \mathrm{a}$ \\
\hline BNT $5 \%$ & & 0,29 & & 1,02 \\
\hline
\end{tabular}

Keterangan: Nilai tengah pada setiap kolom yang diikuti dengan huruf yang sama tidak berbeda nyata menurut uji BNT pada taraf $5 \%$. 
Tabel 3. Pengaruh aplikasi herbisida atrazin terhadap bobot kering gulma golongan golongan rumput

\begin{tabular}{lcccc}
\hline \multirow{2}{*}{ Perlakuan } & \multicolumn{2}{c}{ 3 Minggu Setelah Aplikasi } & \multicolumn{2}{c}{ 6 Minggu Setelah Aplikasi } \\
\cline { 2 - 5 } & Asli & $\sqrt{ } \sqrt{ }(\mathrm{X}+0,5)$ & Asli & $\sqrt{ } \sqrt{ }(\mathrm{X}+0,5)$ \\
\hline Atrazin $1,20 \mathrm{~kg} / \mathrm{ha}$ & 0,00 & $\ldots \ldots \ldots \ldots\left(\mathrm{g} / 0,5 \mathrm{~m}^{2}\right)$ & $\ldots \ldots \ldots \ldots \ldots \ldots \ldots \ldots$ & \\
Atrazin $1,80 \mathrm{~kg} / \mathrm{ha}$ & 0,00 & $0,70 \mathrm{~b}$ & 9,10 & $1,29 \mathrm{ab}$ \\
Atrazin $2,40 \mathrm{~kg} / \mathrm{ha}$ & 0,00 & $0,70 \mathrm{~b}$ & 3,60 & $1,09 \mathrm{bc}$ \\
Atrazin $3,00 \mathrm{~kg} / \mathrm{ha}$ & 0,00 & $0,70 \mathrm{~b}$ & 6,15 & $1,16 \mathrm{bc}$ \\
Penyiangan manual & 0,64 & $0,70 \mathrm{~b}$ & 4,01 & $1,11 \mathrm{bc}$ \\
Kontrol & 0,73 & $1,02 \mathrm{a}$ & 0,60 & $0,99 \mathrm{c}$ \\
BNT $5 \%$ & $1,08 \mathrm{a}$ & 19,69 & $1,42 \mathrm{a}$ \\
\hline
\end{tabular}

Keterangan: Nilai tengah pada setiap kolom yang diikuti dengan huruf yang sama tidak berbeda nyata menurut uji BNT pada taraf 5\%.

\section{Koefisien Komunitas (C)}

Menurut Marsal et al. (2015), koefisien komunitas gulma berguna untuk membandingkan dua komunitas atau dua macam vegetasi dari dua areal. Pada 3 MSA (Tabel 4), aplikasi herbisida atrazin dosis $1,20-3,00 \mathrm{~kg} / \mathrm{ha}$ dibandingkan dengan kontrol memiliki tingkat kesamaan jenis gulma antara 0 - 19\%. Aplikasi herbisida atrazin dosis $1,20-3,00 \mathrm{~kg} / \mathrm{ha}$ dibandingkan kontrol memiliki tingkat kesamaan jenis gulma antara 57 - 71\% pada 6 MSA.

Jenis gulma yang mendominasi pada perlakuan herbisida atrazin dosis $1,20 \mathrm{~kg} / \mathrm{ha}$, $1,80 \mathrm{~kg} / \mathrm{ha}$, dan $2,40 \mathrm{~kg} / \mathrm{ha}$ adalah Calopogonium mucunoides, dan pada perlakuan dosis $3,00 \mathrm{~kg} / \mathrm{ha}$ adalah gulma Eleusine indica. Sedangkan, petak perlakuan kontrol didominasi oleh gulma Richardia brasiliensis. Berdasarkan penelitian aplikasi herbisida atrazin dosis $1,20-3,00 \mathrm{~kg} / \mathrm{ha}$ menyebabkan terjadinya perubahan komposisi jenis gulma dari Richardia brasiliensis menjadi Calopogonium mucunoides pada 3 dan 6 MSA.

Adanya tekanan selektifitas yang baik dari herbisida serta perbedaan tanggapan masing-masing jenis gulma terhadap herbisida dapat menyebabkan perubahan komunitas gulma. Menurut Apriadi et al. (2013), penyebab terjadinya perubahan komposisi gulma juga dipengaruhi oleh kecepatan pertumbuhan gulma yang memungkinkan tumbuhnya spesies-spesies gulma yang sebelumnya tertekan. Hal ini sesuai dengan pendapat Utomo dan Nazaruddin (1998), salah satu cara pengendalian gulma yang dapat menekan pertumbuhan spesies gulma tertentu yaitu dengan mengaplikasikan herbisida pada lahan budidaya, tetapi hal ini dapat mengakibatkan terjadinya perubahan komunitas dan populasi gulma atau tumbuhnya spesies gulma baru.

\section{Tinggi Tanaman Jagung}

Pada 3 MSA aplikasi herbisida atrazin semua taraf dosis yang diuji terkecuali dosis $3,00 \mathrm{~kg} / \mathrm{ha}$ memiliki tinggi tanaman tidak berbeda dibandingkan kontrol dan setara dengan penyiangan manual (Tabel 5). Hal ini sesuai dengan penelitian Umiyati (2019), bahwa pada fase vegetatif awal tanaman jagung masih belum dapat menyerap unsur hara secara optimum dikarenakan akar lateral yang terbentuk masih muda dan kebutuhan unsur hara pada fase vegetatif awal relatif masih sedikit. Sehingga pada 3 MSA persaingan penyerapan unsur hara antara tanaman budidaya dengan gulma tidak signifikan.

Pada 6 dan 9 MSA menunjukkan bahwa tinggi tanaman jagung lebih tinggi pada perlakuan aplikasi herbisida atrazin pada semua taraf dosis yang diuji. Hal tersebut ditunjukkan dengan tinggi tanaman jagung pada semua taraf dosis 
yang diuji lebih tinggi dibandingkan dari kontrol dan setara dengan penyiangan manual. Pada kontrol diduga terdapat banyak gulma yang tumbuh dan menimbulkan kompetisi dalam penyerapan unsur hara terhadap tanaman jagung. Hal ini didukung oleh pernyataan Sembodo
(2010), bahwa pertumbuhan gulma yang cepat menyebabkan kompetisi dengan tanaman untuk mendapatkan sarana tumbuh yang ada, sehingga produktivitas tanaman budidaya akan menurun.

Tabel 4. Perubahan komposisi gulma akibat apliksi herbisida atrazin di lahan jagung pada 3 dan 6 MSA

\begin{tabular}{rcc}
\hline \multirow{2}{*}{ Perbandingan } & \multicolumn{2}{c}{ Nilai Koefesien Komunitas (\%) } \\
\cline { 2 - 3 } & 3 MSA & 6 MSA \\
\hline Atrazin $1,20 \mathrm{~kg} / \mathrm{ha}$ vs kontrol & 19 & 67 \\
Atrazin $1,80 \mathrm{~kg} / \mathrm{ha}$ vs kontrol & 0 & 71 \\
Atrazin $2,40 \mathrm{~kg} / \mathrm{ha}$ vs kontrol & 19 & 71 \\
Atrazin $3,00 \mathrm{~kg} / \mathrm{ha}$ vs kontrol & 0 & 57 \\
Penyiangan manual vs kontrol & 84 & 56 \\
\hline
\end{tabular}

Tabel 5. Tinggi tanaman jagung akibat aplikasi herbisida atrazin

\begin{tabular}{lccc}
\hline \multirow{2}{*}{ Perlakuan } & \multicolumn{3}{c}{ Tinggi Tanaman $(\mathrm{cm})$} \\
\cline { 2 - 4 } & $3 \mathrm{MSA}$ & $6 \mathrm{MSA}$ & $9 \mathrm{MSA}$ \\
\hline Atrazin $1,20 \mathrm{~kg} / \mathrm{ha}$ & $54,30 \mathrm{~b}$ & $176,32 \mathrm{ab}$ & $218,20 \mathrm{ab}$ \\
Atrazin $1,80 \mathrm{~kg} / \mathrm{ha}$ & $59,90 \mathrm{ab}$ & $178,90 \mathrm{ab}$ & $223,03 \mathrm{ab}$ \\
Atrazin $2,40 \mathrm{~kg} / \mathrm{ha}$ & $57,67 \mathrm{ab}$ & $180,25 \mathrm{ab}$ & $225,95 \mathrm{a}$ \\
Atrazin $3,00 \mathrm{~kg} / \mathrm{ha}$ & $61,70 \mathrm{a}$ & $187,30 \mathrm{a}$ & $226,80 \mathrm{a}$ \\
Penyiangan manual & $58,02 \mathrm{ab}$ & $169,65 \mathrm{bc}$ & $217,30 \mathrm{~b}$ \\
Kontrol & $54,95 \mathrm{~b}$ & $158,82 \mathrm{c}$ & $207,25 \mathrm{c}$ \\
\hline BNT $5 \%$ & 5,85 & 14,35 & 8,6 \\
\hline
\end{tabular}

Keterangan: Nilai tengah pada setiap kolom yang diikuti dengan huruf yang sama tidak berbeda nyata menurut uji BNT pada taraf $5 \%$.

Tabel 6. Panjang dan diameter tongkol tanaman jagung

\begin{tabular}{lcc}
\hline Perlakuan & Panjang tongkol $(\mathrm{cm})$ & Diamater tongkol $(\mathrm{cm})$ \\
\hline Atrazin $1,20 \mathrm{~kg} / \mathrm{ha}$ & $17,06 \mathrm{ab}$ & $4,17 \mathrm{ab}$ \\
Atrazin $1,80 \mathrm{~kg} / \mathrm{ha}$ & $17,41 \mathrm{a}$ & $4,21 \mathrm{a}$ \\
Atrazin $2,40 \mathrm{~kg} / \mathrm{ha}$ & $17,17 \mathrm{a}$ & $4,17 \mathrm{ab}$ \\
Atrazin $3,00 \mathrm{~kg} / \mathrm{ha}$ & $17,26 \mathrm{a}$ & $4,19 \mathrm{ab}$ \\
Penyiangan manual & $17,92 \mathrm{a}$ & $4,17 \mathrm{ab}$ \\
Kontrol & $15,92 \mathrm{~b}$ & $4,08 \mathrm{~b}$ \\
\hline BNT 5\% & 1,18 & 0,13 \\
\hline
\end{tabular}

Keterangan: Nilai tengah pada setiap kolom yang diikuti dengan huruf yang sama tidak berbeda nyata menurut uji BNT pada taraf $5 \%$. 
Tabel 7. Bobot 100 butir dan produksi jagung pipilan

\begin{tabular}{llll}
\hline Perlakuan & Bobot 100 butir $(\mathrm{g})$ & $\begin{array}{c}\text { Produksi pipilan per } \\
\text { petak }\left(\mathrm{kg} / 6 \mathrm{~m}^{2}\right)\end{array}$ & $\begin{array}{c}\text { Produksi jagung } \\
\text { pipilan }(\mathrm{t} / \mathrm{ha})\end{array}$ \\
\hline Atrazin $1,20 \mathrm{~kg} / \mathrm{ha}$ & $24,95 \mathrm{a}$ & $3,72 \mathrm{ab}$ & $6,21 \mathrm{ab}$ \\
Atrazin $1,80 \mathrm{~kg} / \mathrm{ha}$ & $27,27 \mathrm{a}$ & $4,03 \mathrm{ab}$ & $6,71 \mathrm{ab}$ \\
Atrazin $2,40 \mathrm{~kg} / \mathrm{ha}$ & $27,80 \mathrm{a}$ & $3,65 \mathrm{~b}$ & $6,09 \mathrm{~b}$ \\
Atrazin $3,00 \mathrm{~kg} / \mathrm{ha}$ & $26,18 \mathrm{a}$ & $3,62 \mathrm{~b}$ & $6,03 \mathrm{~b}$ \\
Penyiangan manual & $28,49 \mathrm{a}$ & $4,23 \mathrm{a}$ & $7,05 \mathrm{a}$ \\
Kontrol & $22,65 \mathrm{a}$ & $2,74 \mathrm{c}$ & $4,87 \mathrm{c}$ \\
\hline BNT $5 \%$ & 7,6 & 0,56 & 0,94 \\
\hline
\end{tabular}

Keterangan: Nilai tengah pada setiap kolom yang diikuti dengan huruf yang sama tidak berbeda nyata menurut uji BNT pada taraf $5 \%$.

\section{Panjang dan Diameter Tongkol}

Aplikasi herbisida atrazin pada dosis 1,80 - 3,00 kg/ha menghasilkan panjang tongkol lebih panjang dibandingkan kontrol dan setara dengan penyiangan manual (Tabel 6). Panjang tongkol memiliki ratarata yang hampir relatif saragam yaitu sekitar 15-18 cm. Diameter tongkol jagung menujukkan bahwa aplikasi herbisida atrazin pada semua taraf dosis uji 1,20 - 3,00 $\mathrm{kg} / \mathrm{ha}$ memiliki diameter tongkol tidak berbeda dibandingkan kontrol dan penyiangan manual (Tabel 6). Hasil menunjukkan diameter tongkol jagung ratarata yang hampir seragam yaitu berkisar 4,04,21 cm. Menurut Suryana (2008), suatu tanaman akan tumbuh dan berkembang dengan subur apabila unsur hara yang diberikan dapat diserap akar dalam betuk yang sesuai dan cukup, hal tersebut menyebabkan kegiatan penyerapan hara dan fotosintesis berjalan dengan baik sehingga fotosintat yang terakumulasi juga ikut meningkat dan akan berpengaruh terhadap pertumbuhan tongkol.

\section{Variabel Hasil}

Aplikasi herbisida atrazin dosis 1,20$3,00 \mathrm{~kg} / \mathrm{ha}$ tidak berpengaruh terhadap bobot biji jagung (Tabel 7). Hal tersebut dapat dilihat dari bobot 100 butir pada dosis 1,20$3,00 \mathrm{~kg} / \mathrm{ha}$ setara dengan penyiangan manual dan kontrol. Menurut Agrita (2012) dalam Wahyudin (2016), komponen bobot 100 butir dapat dipengaruhi oleh faktor genotip dan lingkungan. Kondisi lingkungan yang paling berpengaruh adalah temperatur pada saat pertumbuhan. Temperatur dapat mempengaruhi ukuran biji maksimum. Ukuran biji maksimum dapat tercapai pada suhu rata-rata $25^{\circ} \mathrm{C}$.

Bobot kering jagung pipilan per petak panen dan bobot jagung pipilan per hektar menunjukkan bahwa seluruh taraf dosis herbisida atrazin dan penyiangan manual tidak mempengaruhi pertumbuhan dan produksi tanaman jagung (Tabel 7). Pada perlakuan kontrol terjadi kompetisi antar gulma dengan tanaman sehingga pertumbuhan dan produksi tanaman jagung lebih rendah dibandingkan dengan seluruh taraf dosis herbisida atrazin serta penyiangan manual. Menurut Fadhly dan Tabri (2007), tingkat persaingan gulma dengan tanaman jagung bergantung pada 4 faktor, antara lain stadia pertumbuhan tanaman, kepadatan gulma, tingkat cekaman air dan hara serta spesies gulma. Apabila dibiarkan atau tidak dilakukan pengendalian gulma dapat secara nyata menekan pertumbuhan dan perkembangan tanaman jagung

\section{Fitotoksisitas terhadap Tanaman Jagung}

Data fitotoksisitas herbisida atrazin pada 1 dan 2 MSA menunjukkan bahwa tidak terdapat gejala keracunan pada tanaman jagung (Zea mays L.) pada petak perlakuan herbisida atrazin. Menurut Tomlin (2011), herbisida atrazin bersifat selektif pada tanaman jagung sehingga tidak menyebabkan keracunan pada tanaman jagung. Hal ini terjadi karena tanaman 
jagung mampu melakukan metabolisme terhadap atrazin dan dikonjugasi oleh asam amino. Sesuai dengan penelitian Khan et al. (2014), aplikasi herbisida atrazin pada lahan tanaman jagung tidak menimbulkan gejala keracunan, baik tunggal maupun campuran.

\section{KESIMPULAN}

Berdasarkan hasil penelitian dapat disimpulkan bahwa herbisida atrazin dosis $1,20-3,00 \mathrm{~kg} / \mathrm{ha}$ efektif mengendalikan gulma total, gulma golongan daun lebar pada 3 dan 6 MSA, sedangkan herbisida atrazin dosis $\quad 1,80-3,00 \quad \mathrm{~kg} / \mathrm{ha}$ mampu mengendalikan gulma golongan rumput hingga 6 MSA dan aplikasi herbisida atrazin menyebabkan terjadi perubahan komposisi gulma pada 3 dan 6 MSA. Selain itu, aplikasi herbisida atrazin dosis 1,20-3,00 $\mathrm{kg} / \mathrm{ha}$ tidak menyebabkan terjadinya fitotoksisitas dan tidak menghambat pertumbuhan serta tidak menurunkan hasil tanaman jagung.

\section{DAFTAR PUSTAKA}

Apriadi, W., D. R. J. Sembodo, dan H. Susanto. 2013. Efikasi Herbisida 2,4 D terhadap Gulma pada Tanaman Padi Sawah (Oryza sativa). J. Agrotek Tropika. 10 (2):79-84.

Badan Pusat Statistik. 2019. Produksi Jagung Indonesia. Diakses dari www.bps.go.id. Pada tanggal 28 September 2019.

Craff, R. dan K.N. Reynor. 2001. Weed Control A Text Book and Manual Second Edition. McGraw-Hill. 503 hlm.

Fadhly, A. F. dan F. Tabri.2007. Pengendalian Gulma pada Pertanaman Jagung.Diakses dari http:/balit.litbang.co.id. bukujagung.pdf pada tanggal 21 Juli 2020.

Khan, H., K. B. Marwat, M. A. Khan, dan S. Hasami. 2014. Herbicidal Control of Parthenium Weed in Maize. Pakistan Journal of botani. 46 (2): 497-504.

Marsal, D., K. P. Wicaksono.dan E. Widaryanto.2015. Dinamika Perubahan Komposisi Gulma pada Tanaman Tebu
Keprasan di Lahan Sistem Reynoso dan Tegalan. J. Produksi Tanaman, 3: 81-90.

Mustajab, D.R. J. Sembodo, dan H. Hamim. 2014. Efikasi Herbisida Atrazin terhadap Gulma Umum pada Lahan Budidaya Tanaman Jagung (Zea mays L.). Jurnal Penelitian Pertanian Terapan, 15(1):8-14.

Owen, M. D. K. 2012. Herbicide Guide of Iowa Corn and Soybean Production.New Options for weed management in 2012.Iowa State University Extension and Outreach. USA. $18 \mathrm{hlm}$.

Pike, D. R., dan E. Knake. 1994. Agricultural Weeds Survey : Illinois, Corn. National Center for food and Agricultural Policy. Washington DC. $38 \mathrm{hlm}$.

Sembodo, D. R. J. 2010. Gulma dan Pengelolaannya. Graha Ilmu. Yogyakarta. $168 \mathrm{hlm}$.

Suryana, N. K., 2008. Pengaruh Naungan dan Dosis Pupuk Kotoran Ayam terhadap Pertumbuhan dan Hasil Paprika (Capsicum annum var. Grossum). J. Agrisains, 4(2):89-95.

Tomlin, C. D. S. 2011. The e-Pesticides Manual version 3.0 (thriteenth edition). British Crop Protection Council.United Stated. 589 hlm.

Umiyati, U., D. Widayat, D. Kurniadie, R. Y. Fadillah, dan Deden. 2019. Pengaruh Campuran Herbisida Atrazin 500 g/l dan Mesotrion $50 \mathrm{~g} / \mathrm{l}$ Terhadap Pertumbuhan Beberapa Jenis Gulma Serta Hasil Jagung (Zea mays L.). J. Agrosintesa, 2(1):9-18.

Utomo M., dan Nazaruddin. 1998. Bertanaman Padi Sawah Tanpa Olah Tanah. Penebar Swadaya. Bogor. $52 \mathrm{hlm}$.

Wahyudin, A., Ruminta, S. A., dan Nursaripah. 2016. Pertumbuhan dan hasil tanaman jagung (Zea mays L.) toleran herbisida akibat pemberian berbagai dosis herbisida kalium glifosat. Jurnal Kultivasi. 15(2).

Williams, M. M., R. A. Boydiston, R. Ed. Peachey, dan D. Robinson. 2011. Significance of atrazine as a Tank-Mix Partner with Tembotrione. Weed Technology. 25(3): 299-302. 